\title{
Percepção ambiental e análise de desenhos sobre a temática reciclagem em uma escola pública estadual da Amazônia Paraense
}

Environmental perception and analysis of drawings on the theme of recycling in a state public school in the Amazon of Pará

Percepción ambiental y análisis de dibujos sobre el tema del reciclaje en una escuela pública estatal en la Amazonía de Pará

Gabriel Neves da Costa ORCID: https://orcid.org/0000-0001-8753-8513 Universidade Federal do Pará, Brasil E-mail: gabrielnevess123@gmail.com Deyvison Luz Santos ORCID: https://orcid.org/0000-0001-7585-9889 Universidade Federal do Pará, Brasil E-mail: deyvisonluz10@gmail.com

Gabrielle de Nazaré Falcão da Silva ORCID: https://orcid.org/0000-0002-8438-5045 Universidade Federal do Pará, Brasil E-mail: gabbifalcao20@gmail.com

Adrielly Bizerra da Silva

ORCID: https://orcid.org/0000-0003-0376-7955 Universidade Federal do Pará, Brasil E-mail: adriellysilva751@gmail.com

Jones Souza Moraes

ORCID: https://orcid.org/0000-0001-9328-5591 Universidade Federal do Pará, Brasil E-mail: jhones244@hotmail.com

Marcos Allan da Silva Linhares ORCID: https://orcid.org/0000-0001-9153-3977 Centro Educacional João Paulo II, Brasil E-mail: marcosallan.18@gmail.com Dioniso de Souza Sampaio ORCID: https://orcid.org/0000-0002-2688-6001 Universidade Federal do Pará, Brasil E-mail: sampaio.ds@gmail.com

\begin{abstract}
Resumo
Este artigo teve como objetivo analisar a percepção ambiental através de desenhos elaborados por alunos acerca da temática reciclagem. Para tanto, foi necessário realizar uma pesquisa qualitativa do tipo exploratória, execução de aula teórica em sala, aplicação de jogo utilizando o tabuleiro com perguntas sobre a reciclagem, e elaboração de desenhos alinhados de descrições escritas produzidos por 21 alunos do $8^{\circ}$ ano do ensino fundamental de uma escola pública estadual da Amazônia Paraense, a fim de levantar informações sobre a percepção dos estudantes sobre o ambiente e ao tema reciclagem. Os desenhos foram analisados utilizando duas categorias que se agruparam da seguinte forma: elementos da natureza e como meio de vida. Dentre os $42(100 \%)$ desenhos elaborados, $37(88,09 \%)$ apresentaram a categoria elementos da natureza. As árvores aparecem em 35 (83,33\%) desenhos, enquanto que o Sol se destaca em $29(69,09 \%)$ desenhos. Além disso, os animais como, borboletas, pássaros, peixes e coelho estiveram presentes em 17 $(40,47 \%)$ desenhos. Foi possível analisar também que dos 42 desenhos, o ser humano aparece apenas em 13 (30,95\%) desenhos. As representações dos alunos sobre a temática reciclagem por meio de desenhos alinhados com descrições possuem muitas situações de desconexão entre o que os alunos escreveram e o desenho elaborado pelos mesmos, uma vez há poucas representações que inseriram a figura humana em suas percepções, dando ênfase na maioria dos desenhos a natureza com maior intensidade. Diante disso, a questão ambiental observada através dos desenhos é essencial na percepção da realidade vivenciada pelos alunos.
\end{abstract}

Palavras-chave: Percepção ambiental; Educação ambiental; Ensino fundamental. 


\begin{abstract}
This article aimed to analyze the environmental perception through drawings made by students about the recycling theme. For that, it was necessary to carry out a qualitative research of the exploratory type, execution of theoretical class in the classroom, application of a game using the board with questions about recycling, and elaboration of aligned drawings of written descriptions produced by 21 students of the 8th grade of elementary school. of a state public school in the Amazon of Pará, in order to gather information about the students' perception of the environment and the recycling theme. The drawings were analyzed using two categories that were grouped as follows: elements of nature and as a way of life. Among the $42(100 \%)$ elaborated drawings, 37 (88.09\%) presented the category elements of nature. The trees appear in $35(83.33 \%)$ drawings, while the Sun stands out in $29(69.09 \%)$ drawings. In addition, animals such as butterflies, birds, fish and rabbits were present in 17 (40.47\%) drawings. It was also possible to analyze that of the 42 drawings, the human being appears only in $13(30.95 \%)$ drawings. The representations of students on the theme of recycling through drawings aligned with descriptions have many situations of disconnection between what students wrote and the drawing made by them, since there are few representations that inserted the human figure in their perceptions, emphasizing the most drawings to nature with greater intensity. Therefore, the environmental issue observed through the drawings is essential in the perception of the reality experienced by the students.
\end{abstract}

Keywords: Environmental perception; Environmental education; Elementary school.

\title{
Resumen
}

Este artículo tuvo como objetivo analizar la percepción ambiental a través de dibujos realizados por estudiantes sobre el tema del reciclaje. Para ello, fue necesario realizar una investigación cualitativa de tipo exploratoria, ejecución de clase teórica en el aula, aplicación de un juego usando el tablero con preguntas sobre reciclaje, y elaboración de dibujos alineados de descripciones escritas producidas por 21 alumnos del $8^{\circ}$ grado de primaria. de una escuela pública estatal en la Amazonía de Pará, con el fin de recopilar información sobre la percepción de los estudiantes sobre el medio ambiente y el tema del reciclaje. Los dibujos se analizaron utilizando dos categorías que se agruparon de la siguiente manera: elementos de la naturaleza y como forma de vida. Entre los 42 (100\%) dibujos elaborados, 37 $(88,09 \%)$ presentaron la categoría elementos de la naturaleza. Los árboles aparecen en 35 (83,33\%) dibujos, mientras que el Sol se destaca en $29(69,09 \%)$ dibujos. Además, animales como mariposas, pájaros, peces y conejos estuvieron presentes en 17 (40,47\%) dibujos. También se pudo analizar que de los 42 dibujos, el ser humano aparece solo en 13 $(30,95 \%)$ dibujos. Las representaciones de los estudiantes sobre el tema del reciclaje a través de dibujos alineados con descripciones tienen muchas situaciones de desconexión entre lo que escribieron los estudiantes y el dibujo realizado por ellos, ya que son pocas las representaciones que insertaron la figura humana en sus percepciones, enfatizando la mayoría de los dibujos a la naturaleza con mayor intensidad. Por tanto, el tema ambiental observado a través de los dibujos es fundamental en la percepción de la realidad vivida por los estudiantes.

Palabras clave: Percepción ambiental; Educación ambiental; Enseñanza fundamental.

\section{Introdução}

A cada novo ano, é notório um crescimento massivo da população mundial, e com isso, a produção de resíduos sólidos tende a aumentar proporcionalmente. Partindo desta realidade, discussões no que diz respeito a Educação Ambiental têm ganhado grande destaque na sociedade, tendo como uma de suas pautas principais o acúmulo de resíduos sólidos e seu descarte de forma incorreta (Alencar, 2005).

A Educação Ambiental é tida como um instrumento de grande importância para a construção de uma consciência crítica reflexiva sobre o ambiente o qual o ser humano está inserido (Bezerra et al., 2017). A percepção sensível que os sujeitos constroem em relação ao seu habitat, sobre os diversos elementos que englobam a paisagem e atmosfera do lugar em que vivem, pode contribuir no processo de estímulo para o senso de responsabilidade com as questões socioambientais que cerceiam a sociedade. Nesse sentido, Leff (2012) diz que tal responsabilidade traria ações com foco na melhoria das condições de vida de todos, fazendo assim, com que se consiga amenizar os problemas que se tem com os resíduos sólidos, incluindo aqui a produção, coleta e transporte até o destino final do lixo.

Para minimizar os impactos relacionados ao lixo no meio ambiente, é necessário realizar a reciclagem. Segundo o artigo $3^{\circ}$, inciso XIV da Política Nacional de Resíduos Sólidos, a reciclagem consiste na mudança do estado físico, físicoquímico ou biológico da matéria prima, onde é ocasionada uma transformação que possibilita gerar novos produtos (Brasil, 2010). 
No Brasil, a reciclagem é normalmente realizada por catadores, intermediários e indústrias recicladoras. Os catadores recolhem e selecionam os materiais que podem ser reciclados, tais como papel, vidro, plástico, e outros, e vendem para os intermediários. Os intermediários são cooperativas, empresas ou associações de catadores que podem realizar o trabalho de coleta e segregação dos materiais, e /ou compram e vendem o que foi coletado para indústrias recicladoras, que são responsáveis pelo reprocessamento dos mesmos (Aquino et al., 2009).

Outro mecanismo de destaque no processo de reciclagem é a logística reversa, a mesma tem sua movimentação de materiais, inversamente aquele que vai do fornecedor para o consumidor (Corrêa \& Silva, 2013). A partir deste método, a destinação adequada de embalagens de defensivos agrícolas no Brasil, aumentou de 31.266 toneladas/ano em 2010 para 45.500 em 2015. Além disso, entre os anos 2010 e 2018, do total de embalagens processadas no país, 93\% tiveram como destino final a reciclagem (ABRELPE, 2019).

De acordo com a pesquisa Ciclosoft, os municípios brasileiros que possuem coleta seletiva passaram de 81 em 1994, para 1227 no ano de 2018, atingindo um total de 35 milhões de pessoas. Nesse contexto, a composição gravimétrica da coleta seletiva realizada pelo estudo, mostrou que, dos materiais coletados, $69 \%$ correspondem a algum tipo de material que serviria para reciclagem (Trevisanuto, 2019).

Faz-se necessário compreender a relação que há entre ser humano e meio ambiente buscando dessa forma uma sensibilização dos indivíduos, fazendo com que estes tenham uma mudança de comportamento e consigam se conscientizar no que diz respeito aos problemas ambientais. Nesse sentido, a percepção ambiental é vista como um meio que ajudará no processo mental se tratando da interação que há entre indivíduos e ambiente os quais estão intimamente ligados. Tal processo trará ao indivíduo uma visão ampla de tudo que o cerca, fazendo assim com que haja um envolvimento consigo e com o outro, expondo os detalhes e os aspectos relacionados aos meios biótico e abiótico que os rodeiam (Barboza et al., 2016).

A percepção é entendida como

a interação do indivíduo com seu meio. Este envolvimento dá-se através dos órgãos do sentido. Para que seja possível percebê-lo, é necessário ter algum interesse no objeto de percepção baseado nos conhecimentos, na cultura, na ética, e na postura de cada um, tornando a percepção diferenciada para o mesmo objeto (Gonçalves et al., 2009, p. 3).

Tuan (1980, p. 75) diz que "a percepção é uma atividade, um estender-se para o mundo. Os órgãos dos sentidos são pouco eficazes quando não são ativamente usados". Nesse sentido, Gonçalves, Lima, \& Marques (2009, p. 3) relatam que

qualquer órgão do corpo humano, os órgãos do sentido também devem ser estimulados para melhorar seu rendimento. Quando as pessoas são incentivadas, podem ver algo que outros não veem, podem sentir e ouvir outros sabores e sons, que não sejam os mesmos que todos estão sentindo ou ouvindo.

O estudo da percepção ambiental é de fundamental importância, é por meio dela que será possível "conhecer a cada um dos grupos envolvidos, facilitando a realização de um trabalho com bases locais, partindo da realidade do público alvo, para conhecer como os indivíduos percebem o ambiente em que convivem, suas fontes de satisfação e insatisfação" (Zago et al., 2020).

A Percepção Ambiental é "uma tomada de consciência do ambiente pelo homem" (Carvalho, 2020, p. 3), ou seja, o Homem tem a possibilidade de compreender o ambiente ao qual está inserido, buscando aprender a proteger, assim como, preservar e cuidar das melhores maneiras possíveis.

As pesquisas relacionadas a questão da percepção ambiental contam com diversas estratégias metodológicas (Gonzalez \& Rocha, 2019). Em se tratando de pesquisas com o público infanto-juvenil, tem-se utilizado os desenhos os quais vem sendo utilizados amplamente em diversos estudos (Telles \& Silva, 2012; Catanhede et al., 2016, Gonzalez \& Rocha, 
2019). O uso dessa ferramenta metodológica se dá pelo rápido acesso e aceitação por parte dos sujeitos pesquisados, assim como pelo fato de ser um meio suave e relaxante e de linguagem universal, além é claro de fornecer uma imagem próxima do que o público infanto-juvenil percebe e conhece sobre determinado assunto (Profice et al., 2013).

Nesse sentido, entende-se que se faz necessário primeiramente compreender as percepções que os alunos têm sobre o ambiente e em relação a reciclagem para assim se pensar em intervenções e processos educativos que ajudarão a fortalecer atitudes de conscientização ambiental. Com isso, este trabalho teve como objetivo analisar a percepção ambiental através de desenhos feitos pelos alunos acerca da temática reciclagem em uma escola pública estadual da Amazônia Paraense.

\section{Metodologia}

A presente pesquisa utilizou a abordagem qualitativa, pois, esse método requer do pesquisador uma estruturação prévia (Marconi \& Lakatos, 2010). Para esta pesquisa "entende-se que, para o seu trato e rigor científico, as teorias aplicáveis foram empregadas no decorrer da investigação" (Santos \& Teixeira, 2017, p. 164).

Ainda de acordo com Marconi e Lakatos (2010, p. 270),

A metodologia qualitativa preocupa-se em analisar e interpretar aspectos mais profundos, descrevendo a complexidade do comportamento humano. Fornece análise mais detalhada sobre as investigações, hábitos, atitudes, tendências de comportamento e etc.

Este trabalho é caracterizado como uma pesquisa exploratória, pois traz um tema ainda pouco estudado: descreve a metodologia de análise de desenho para compreender a percepção dos alunos em relação ao ambiente e ao tema reciclagem. A pesquisa exploratória dar suporte ao pesquisador para descrever com mais precisão o problema, nesse sentido "trata-se de uma abordagem adotada para a busca de maiores informações sobre determinado assunto" (Gil, 2006, p. 41).

A pesquisa baseia-se também numa metodologia descritiva, pois

a pesquisa procura abranger aspectos variados de um contexto social, no caso a percepção socioambiental através de desenhos. Também busca explicação acerca de relações entre fenômenos à medida que analisa a opinião dos participantes sobre a interpretação de seus desenhos e a relação entre sociedade e natureza (Santos \& Teixeira, 2017, p. 164).

A pesquisa foi realizada na Escola Estadual Pe. Luiz Gonzaga situada na área urbana do município de Bragança. Esta escola atende alunos de toda cidade e também do meio rural. A escola recebe alunos das séries finais, do ensino fundamental, ensino médio e também da Educação de Jovens e Adultos. O município de Bragança está localizado na região nordeste do Estado do Pará, em uma distância de 210 km da capital Belém e possui uma população estimada de 128.914 habitantes (IBGE, 2019). O município tem como base econômica a pecuária, a agricultura e a pesca.

A pesquisa contou com alunos do ensino fundamental onde participaram discentes da turma do $8^{\circ}$ ano do período matutino $(\mathrm{n}=21)$. A escolha da série partiu do princípio de que os alunos do $8^{\circ}$ ano já conseguem "atribuir significado aos elementos do meio, ou seja, conseguem fazer uma análise mais detalhada dos componentes do meio e entender como eles interagem" (Pereira et al., 2016).

Buscou-se analisar a percepção ambiental e da temática reciclagem, a partir de desenhos alinhados de descrições escritas, produzidos pelos participantes, em dois, de 3 encontros.

Os primeiros desenhos alinhados de descrições, foram produzidos pelos alunos no primeiro encontro, e tiveram como objetivo coletar o conhecimento prévio dos mesmos em se tratando da temática reciclagem. A produção iniciou-se a partir da compreensão da frase "Expressem na forma de desenho seu entendimento a respeito do tema Reciclagem. O que é? Como é feita? Em seguida, descreva seu desenho na forma escrita, em até cinco linhas". 
Posteriormente, no segundo encontro, a intervenção pedagógica iniciou-se com uma aula teórica para situar os alunos quanto o tema educação ambiental com ênfase em reciclagem, foi realizada uma palestra abordando tópicos como: tipos de resíduos sólidos, diferenças entre resíduo orgânico e inorgânico, origem dos resíduos, despejo inadequado e adequado de resíduos sólidos, coleta seletiva e reciclagem. Somado a isso, foi posto em prática o jogo "tabuleiro da reciclagem com roleta de perguntas", com o intuito de auxiliar e promover a aquisição de saberes.

O jogo foi formado por um tabuleiro desenvolvido de TNT, EVA e fita dupla face, contendo 18 casas, das quais, 16 foram enumeradas e 2 continham as frases "volte uma casa" e "volte duas casas". Somado a isso, o jogo foi composto por um dado feito de papelão e EVA, e uma roleta de $1 \mathrm{~m}$ desenvolvida a partir de madeira e EVA, contendo 16 perguntas acerca do tema reciclagem (Figura 1).

Figura 1 - Tabuleiro e roleta utilizados na intervenção pedagógica.
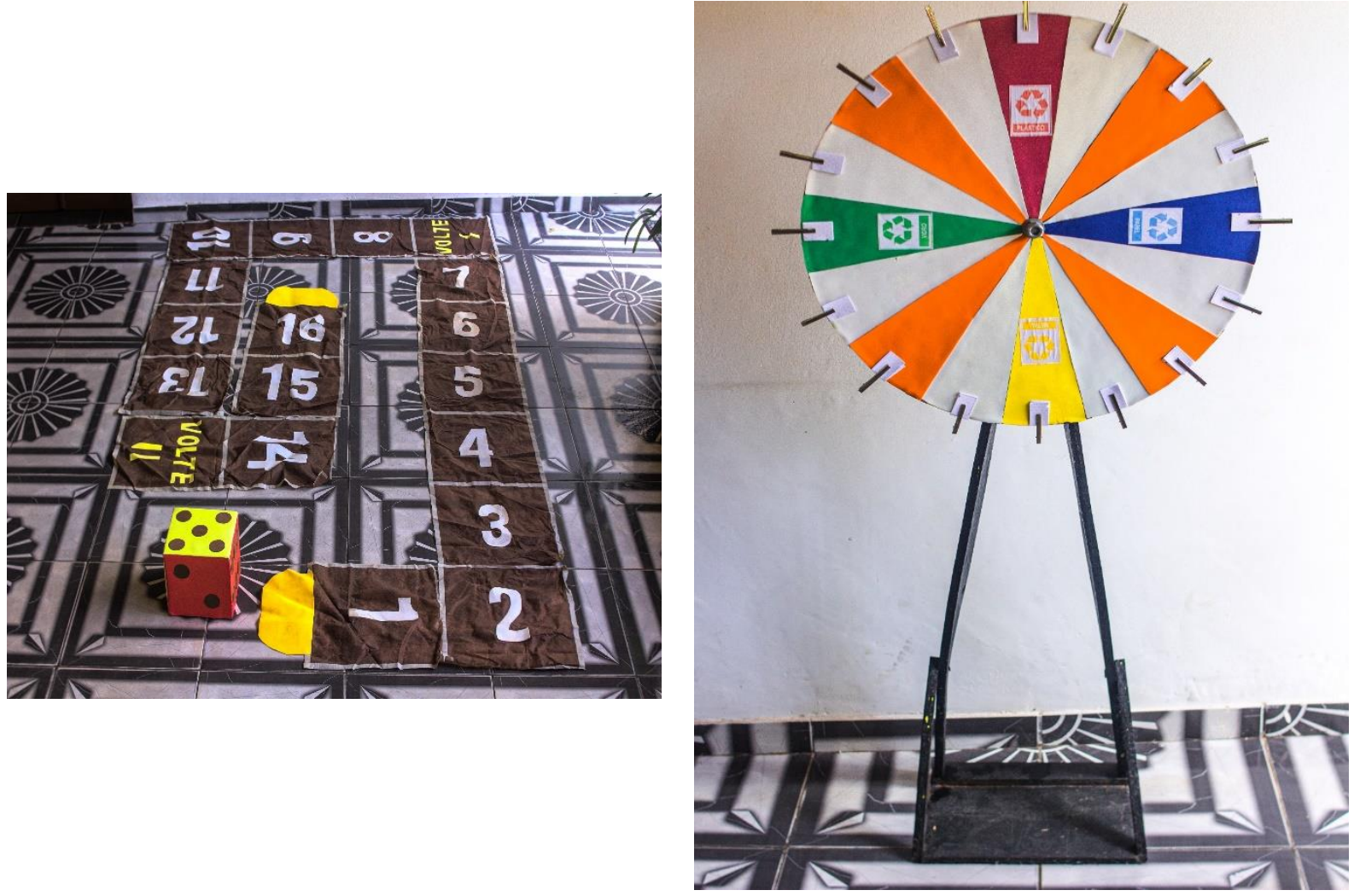

Fonte: Dados da pesquisa.

Para a realização do jogo, a turma foi dividida em duas equipes, onde cada uma possuía um representante. As equipes tinham como objetivo responder as perguntas de forma correta dentro do tempo estabelecido, até que uma delas atingisse primeiro a linha de chegada do tabuleiro, tornando-se vencedora.

O jogo iniciou-se com os representantes na largada do tabuleiro, e de forma concedida, um dos representantes lança o dado e dirigisse até a casa do tabuleiro que a numeração do dado indicou. Em seguida, o mesmo gira a roleta3 e com a ajuda de sua equipe possui 1 minuto para que seja respondida de forma correta a pergunta indicada. Se o participante acertar a pergunta, o mesmo permanece na casa em que o dado parou, caso responda de forma incorreta, o participante volta para seu local anterior a jogada do dado. Caso termine o tempo ou o participante responda à pergunta de forma incorreta, a vez passa para o outro jogador.

Adiante, no terceiro encontro, os alunos produziram novos desenhos com descrições para que fossem coletados os 
conhecimentos construídos após intervenção pedagógica.

\section{Resultados e Discussão}

\subsection{Percepção ambiental dos alunos a partir dos desenhos}

Esta pesquisa contou com 21 participantes, sendo 43\% (n=09) do sexo masculino e 57\% (n=12) do sexo feminino com faixa etária entre 13 e 14 anos, com dois desenhos por aluno, obtendo um total de 42 desenhos, elaborados em dois dos três encontros realizados com a turma.

O resultado da análise do corpus da pesquisa trouxe-nos elementos que podem auxiliar na compreensão da percepção ambiental dos alunos. Quando se refere na percepção ambiental é importante ressaltar que é possível entender as condutas humanas através do comportamento. Para Silva (2013, p. 13),

a percepção é um fator presente em toda a atividade humana, portanto tem um efeito marcante no envolvimento deste com o sentir, tocar, ver e perceber, influenciando diretamente na conduta humana frente as suas ações. Ela pode fornecer a compreensão das interações homem/meio ambiente constituindo-se em um importante campo para pesquisas interdisciplinares. Assim, constata-se a real importância de conhecer e perceber as relações entre os grupos humanos e os ambientes naturais.

Assim, através da percepção ambiental é possível tomar consciência do meio ambiente, perceber o quanto é importante compreender as inter-relações entre o homem e o ambiente, pois, conhecendo e compreendendo o comportamento e atitudes dos indivíduos poderá realizar um trabalho de conservação e manutenção do ambiente.

Sauvé (2005) propõe sete categorias de análise para as representações do meio ambiente, para este trabalho foram utilizadas duas categorias de análise que se agruparam da seguinte forma: elementos da natureza e como meio de vida.

Dentre os 42 desenhos (100\%) feitos pelos alunos, 88,09\% ( $n=37)$ apresentam a categoria elementos da natureza. As árvores aparecem em 83,33\% ( $\mathrm{n}=35)$ apresentando nos desenhos cores fortes e algumas das vezes frutas. Outro elemento que se sobressai nas produções dos alunos destaca-se o sol com 69,09\% $(\mathrm{n}=29)$ dos desenhos. As borboletas, pássaros, peixes e coelho também foram ilustrados em 40,47\% ( $\mathrm{n}=17$ ) dos desenhos, na Figura 2 estão representados os principais elementos da natureza desenhados pelos alunos. 
Figura 2 - Principais elementos da Natureza presentes nos desenhos dos alunos.
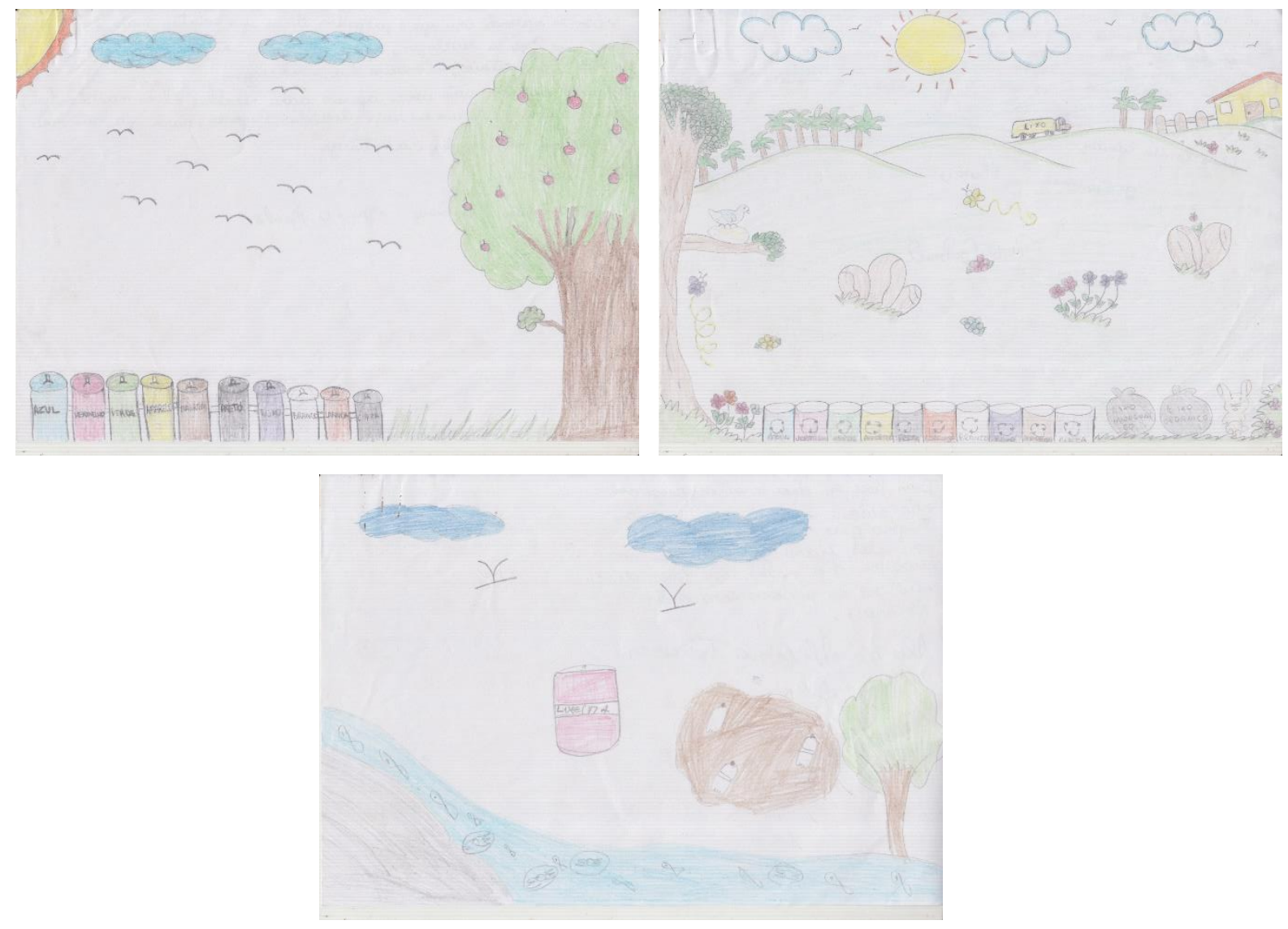

Fonte: Desenhos dos alunos do $8^{\circ}$ ano do Ensino Fundamental.

Os dados obtidos neste trabalho corroboram com os achados de Pereira et al. (2016), que ao analisar as percepções ambientais reveladas por alunos do ensino Fundamental da Escola Estadual Angelina Franciscon Mazutti constatou que as árvores, o sol e os animais foram os elementos da natureza que mais apareceram nos desenhos dos alunos.

O trabalho realizado por Cantanhede et al. (2016) que tinha como objetivo realizar a análise da percepção ambiental de alunos através de desenhos, constatou também que os elementos da natureza apareceram com maior frequência nas produções e conforme os autores as árvores, a maioria com frutos, foram as mais representadas.

Nos desenhos dos alunos foram constatados que o ambiente é tido como um lugar para viver e praticar esportes, isso é evidenciado em 16,66\% $(n=7)$ dos desenhos (Figura 3). Nas ilustrações, podem ser vistos elementos como ruas e casas em meio a outros componentes da natureza, bem como a presença de pessoas praticando esporte no ambiente natural, contemplando assim a categoria meio de vida.

No trabalho de Pereira et al., (2016) foi possível constatar que a categoria meio de vida também apresentou características idênticas com as encontradas neste trabalho, principalmente no que tange as casas em meio a natureza. 
Figura 3 - Representação da categoria meio de vida.

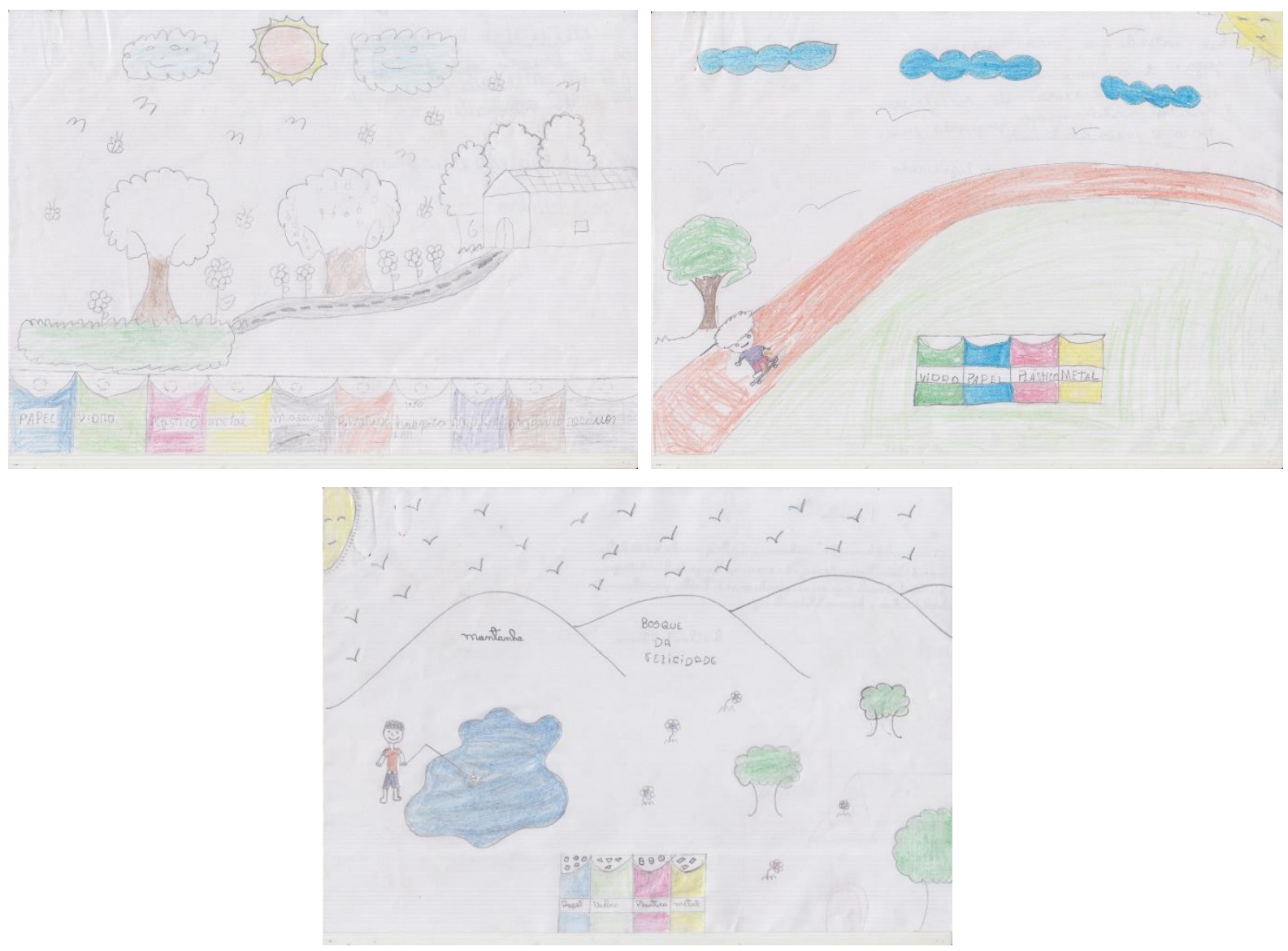

Fonte: Desenhos dos alunos do $8^{\circ}$ ano do Ensino Fundamental.

Outro aspecto importante analisado a partir dos desenhos dos alunos foi a de que a figura humana é posta como um ser a parte da natureza, das 42 representações o ser humano aparece apenas em 13 ilustrações o que corresponde a 30,95\% dos desenhos. Para Pereira et al. (2016), a noção que se tem de ambiente é somente aquela de natureza intocada pelo Ser Humano e isso se torna um obstáculo para a Educação Ambiental, por trazer uma concepção incompleta, já que os problemas ambientais que nos rodeiam estão ligados diretamente com a questão social, de como se dá a relação sociedade e meio ambiente.

O estudo da percepção ambiental realizada neste trabalho é uma contribuição para que os alunos tomem consciência que precisam buscar uma melhor qualidade de vida e estes possam buscar meios de ajudar na preservação dos valores sociais, morais e ambientais tendo como suporte a Educação Ambiental. De acordo com Sachs (1986) é com a percepção ambiental que será possível fazer um planejamento eficaz para a realização de um trabalho voltado para a Educação Ambiental, fazendo com que se tenha o mínimo de impactos ambientais, com bases locais, partindo da própria realidade do público alvo.

Nesse sentido, Silva (2013) nos diz que a percepção ambiental está estreitamente ligada com as atividades desenvolvidas pela Educação Ambiental, pois o estudo da percepção ambiental se torna de grande relevância para que assim se tenha uma maior compreensão das inter-relações existentes entre o Ser Humano e o meio ambiente, suas expectativas, satisfações, julgamentos e condutas. 


\subsection{Representações da temática reciclagem por meio de desenhos alinhados com descriçães antes e pós intervenção pedagógica}

Nessa seção vamos analisar as representações da temática reciclagem que foram reveladas pelos desenhos alinhados com descrições construídas antes e pós intervenção pedagógica. De início foi pedido aos alunos da turma que expressassem em forma de desenho o seu entendimento a respeito do tema Reciclagem, partindo das seguintes indagações: O que é e como é feita? Em seguida, eles foram estimulados a descrever seu desenho na forma escrita, em até cinco linhas.

Os desenhos alinhados com descrições produzidos nesse primeiro momento mostraram que das 21 ilustrações apresentadas apenas uma trouxe elementos sobre a reciclagem. Isso é evidenciado no desenho alinhado com descrição do aluno A, onde este diz que "a reciclagem é um meio de aproveitar os materiais como: papel, vidro, plástico e metal para a confecção de novos produtos e que a reciclagem é feita por um depósito". O mesmo ainda revela que para que a "reciclagem seja feita com sucesso é bom que as pessoas já deixem seus lixos separados" (Figura 4). No trabalho realizado por Cândido (2013) ao avaliar o grau de atendimento sobre o tema reciclagem de alunos do Ensino Fundamental constatou-se que a maioria dos alunos apresenta conhecimento no que diz respeito aos materiais básicos que precisam ser reaproveitados como papel, garrafas plásticas, vidro e metal.

Figura 4 - Entendimento sobre o que é a reciclagem e como é feita na percepção do aluno A.

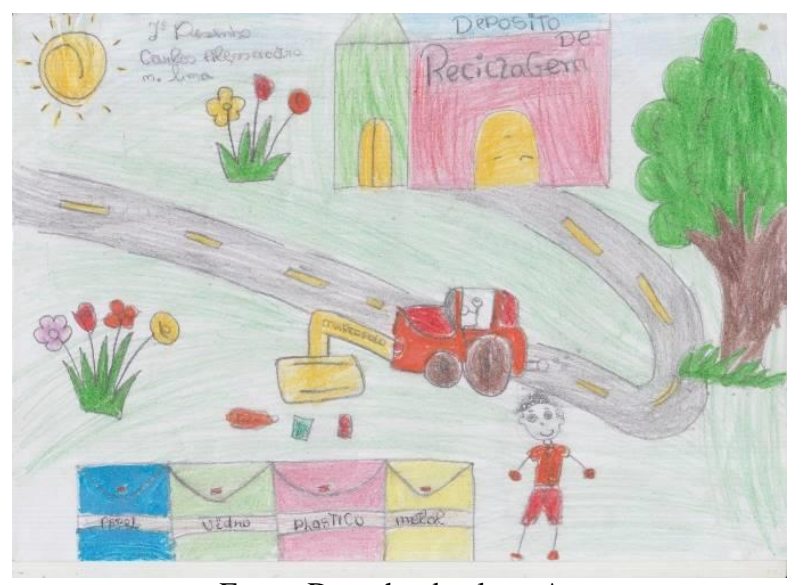

Fonte: Desenho do aluno A.

Apesar da maioria dos alunos não apresentarem uma definição específica para a reciclagem e como ela é feita, os desenhos mostram que estes compreendem que há uma relação entre lixo e meio ambiente que precisa ser melhor compreendida e trabalhada em sala de aula, tal afirmação vai ao encontro dos resultados obtidos por Cândido (2013).

Nesse primeiro momento foi possível observar que das 21 ilustrações 26,19\% (n=11) mostram que os alunos têm conhecimento da importância de fazer a separação do lixo para melhor recolhimento da equipe de limpeza da cidade, estes trazem em seus desenhos as lixeiras para a coleta seletiva, por mais que os alunos não tenham clareza do que seja o processo de reciclagem estes apresentam conhecimento em relação a separação de lixo nas lixeiras corretas (Figura 5). 
Figura 5 - Separação do lixo para coleta seletiva.
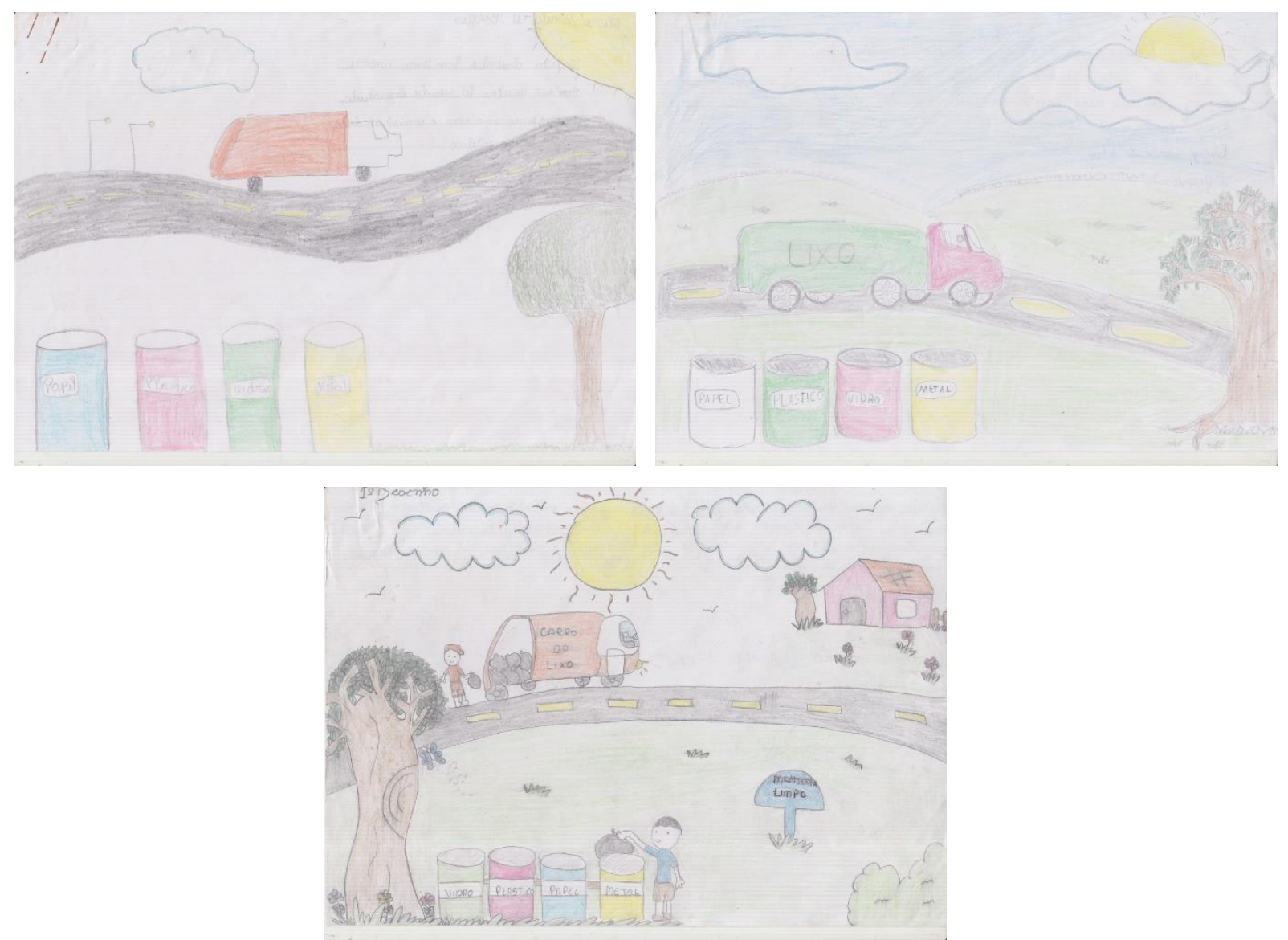

Fonte: Desenhos dos alunos do $8^{\circ}$ ano do Ensino Fundamental.

De acordo com Bezerra et al., (2017, p. 2) “a coleta seletiva de lixo é um processo que consiste na separação e recolhimento dos resíduos descartados por empresas e pessoas". Ainda de acordo com os autores a coleta seletiva possibilita “o maior aproveitamento do resíduo, que antes era descartado e como consequência do seu não aproveitamento aumentaria a quantidade de lixo causando grandes problemas ambientais (p.5).

Verifica-se também nos desenhos dos alunos, que estes têm conhecimento apenas de quatro lixeiras para a coleta seletiva e suas respectivas cores: metal-amarelo, vidro-verde, plástico-vermelho e papel-azul.

A aluna B em seu desenho com descrição disse que "a coleta seletiva de lixo é bom para a sociedade, pois ajuda o meio ambiente fazendo com que se tenha uma baixa poluição dos solos e dos rios”, tal afirmação vai ao encontro daquela posta por Bezerra et al., (2017) que dizem que a coleta seletiva traz grandes vantagens para o meio ambiente, diminuindo a poluição.

Após esse primeiro encontro com a turma, foi possível se pensar num projeto de intervenção pedagógica que viabilizasse o aprendizado dos alunos em relação à temática reciclagem. As intervenções pedagógicas de acordo com Soares (2005, p. 15) “tem sido objeto de reflexão de muitos educadores e teóricos há muito tempo". A autora ainda evidencia a importância da intervenção nos contextos de aprendizagens principalmente no que tange a participação do educador, pois é ele que deve se atentar para os processos que serão adotados na execução do projeto de intervenção. A partir das intervenções feita pelo educador que os alunos poderão "elaborar conceitos provenientes de ações reflexivas internas, as quais não seriam possíveis sem uma provocação de outrem" (Soares, 2005, p. 16). 
Nesse sentido, o projeto de intervenção foi realizado no segundo encontro com a turma. Foi organizada uma exposição teórica, abordando temas como reciclagem mostrando os tipos de resíduos sólidos, diferenças entre resíduo orgânico e inorgânico, origem dos resíduos, despejo inadequado e adequado de resíduos sólidos, coleta seletiva e reciclagem. E para complementar foi utilizado o jogo tabuleiro da reciclagem com roleta de perguntas, com o intuito de auxiliar e promover a aquisição de saberes.

No terceiro encontro pós intervenção pedagógica foi pedido aos alunos que fizessem novos desenhos para assim analisar os novos conhecimentos construídos em relação ao que é reciclagem e como é feita. Das 21 ilustrações foi possível observar que o aluno A novamente foi o único que apresentou definição para a reciclagem dizendo que

"a reciclagem é feita por um depósito, onde o lixo é transformado em novos produtos, por exemplo: se o papel não tem mais nenhuma utilidade para a pessoa, ela pega esse papel coloca na lixeira para a coleta seletiva, depois esse papel é recolhido pelos catadores e é levado para a indústria onde é transformado em um novo papel" (Aluno A).

Nas palavras do aluno o processo de reciclagem trata o lixo como matéria-prima a ser aproveitada para fazer novos produtos que serão reinseridos no mercado. Nesse sentido, reciclar é "refazer o ciclo, permitindo trazer de volta à origem, sob a forma de matéria-prima aqueles materiais que não se degradam facilmente e que poderão ser reprocessados, mantendo as suas características básicas" (Valle, 1995, p.71). Podemos também dizer que a "reciclagem consiste em submeter produtos existentes no lixo a processos de transformação, com o intuito de gerar um novo produto" (Rouquayrol \& Almeida Filho, 1999, p. 426).

Assim, em uma escala menor poderíamos dizer que a reciclagem se concretiza sempre que se encontra um novo uso para alguma coisa que, até então, já não teria nenhuma utilidade, os quais são coletados e separados para serem usados como matéria-prima na fabricação de novos produtos.

Analisando os novos desenhos verificou-se que 100\% (n=21) das ilustrações mostram que os alunos adquiriram novos conhecimentos em relação as lixeiras para a coleta seletiva do lixo, isso é evidenciando nos desenhos abaixo e foram postos pós intervenção pedagógica (Figura 6). As novas informações adquiridas contribuíram para uma nova percepção ambiental dos alunos. Fica evidente, portanto, que ao adquirir novas informações, nossa percepção se altera. 
Figura 6 - Conhecimento dos alunos de novas lixeiras para a coleta seletiva.
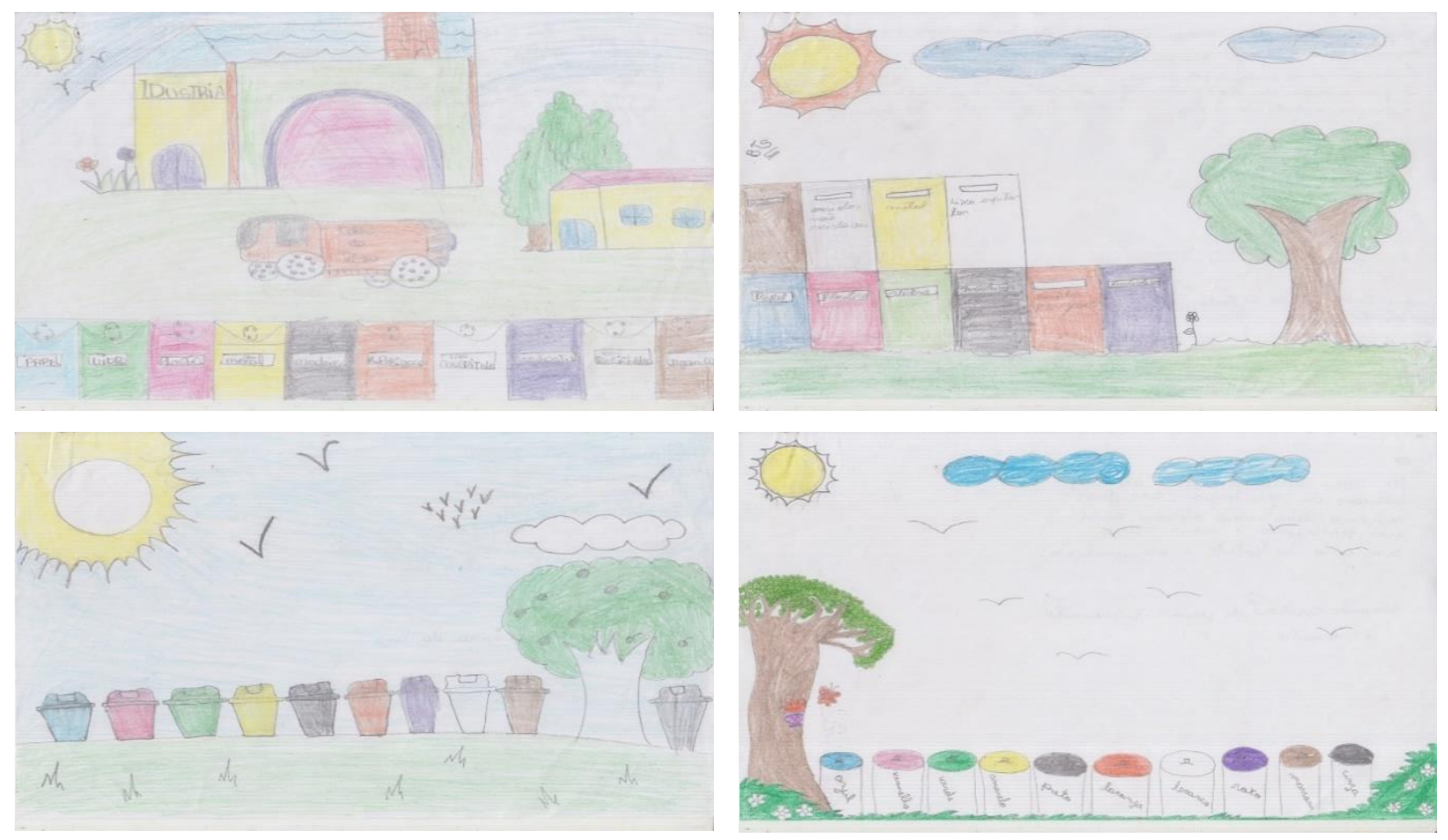

Fonte: Desenhos dos alunos do $8^{\circ}$ ano do Ensino Fundamental.

Nesse trabalho, verificamos que os alunos conseguiram assimilar as cores e finalidades destas para a coleta seletiva, pois estes em suas descrições relatam que para cada cor existe um material específico. Para afirmar a colocação dos alunos trazemos como aporte a Resolução do CONAMA n 275 de 25 de abril de 2001, que estabelece o código de cores para os diferentes tipos de resíduos como: azul - papel e papelão, vermelho - plástico, verde - vidro, amarelo - metal, marrom resíduos orgânicos, preto - madeira, roxo - resíduos radioativos, laranja - resíduos perigosos, branco - resíduos ambulatoriais e de serviço de saúde, cinza - resíduo geral não reciclável ou misturado, ou contaminado não passível de separação.

Foi possível constatar com a realização deste trabalho que as representações sobre a temática reciclagem por meio de desenhos alinhados com descrições possuem muitas situações de desconexão entre o que os alunos escreveram e o desenho elaborado pelos mesmos, diferente dos trabalhos realizados por Torres (2010) e Pereira et al., (2016) onde as frases estavam sempre relacionadas com os desenhos.

Os PCNs (1998) consideram que, ao final do ensino fundamental, os alunos sejam capazes de analisar fatos e situações de modo ambientalmente crítico, adotando posturas e interações sustentáveis, seja no ambiente escolar, familiar ou em comunidade. Os PCNs (1998) ressaltam também, a importância de vincular as temáticas de estudo, com o contexto físico, biológico, histórico, social e político do aluno, visto que, este método é um facilitador do ensino aprendizagem.

Em contrapartida, a temática reciclagem ainda é pouca exposta nas series do ensino fundamental; com frequência, quando lecionada, limita-se ao conceito dos três " $R$ " (reduzir, reutilizar e reciclar). Nesse contexto, um estudo realizado por Caldeira et al. (2012), mapeou 43 colégios de rede pública no município de Ponta Grossa-PR, e mostrou que apenas 12 deles apresentam assuntos referentes a educação ambiental, e 8 mostraram desenvolver algum tipo de projeto relativo à reciclagem e coleta seletiva.

No trabalho de Souza et al. (2014) sobre manejo de resíduos sólidos e reciclagem no cotidiano escolar, métodos de ensino como palestras, seminários, atividades práticas e oficinas, mostraram-se bastante eficientes ao evidenciar senso crítico 
ambiental nos alunos. Resultado similar foi observado no trabalho de Garçone (2019), onde foram utilizados diferentes tipos de jogos educativos voltados para o ensino da reciclagem, dentre eles o jogo de tabuleiro.

Os Parâmetros Curriculares Nacionais - PCNs (1998), propõem que as temáticas: Meio Ambiente e Reciclagem, sejam agregadas ao currículo escolar por se tratarem de um tema transversal, logo, possuem conceitos de cidadania e promovem a construção de melhores relações sociais. Ademais, ao se abordar esses temas, deve ser empregada a interdisciplinaridade, técnica essa que potencializa o aprendizado e permite discutir os assuntos em questão em diferentes matérias.

\section{Considerações Finais}

O estudo da percepção ambiental realizado com os alunos do $8^{\circ}$ ano do ensino fundamental de uma escola do Município de Bragança-Pará, mostrou que as representações dos alunos sobre a temática reciclagem por meio de desenhos alinhados com descrições demostraram que os mesmos percebem o meio ambiente com maior intensidade, inserindo a figura humana em poucos desenhos.

Essa noção de ambiente sem a presença humana é considerada um grande obstáculo para a Educação Ambiental, pois sabe-se que os impactos ambientais são ocasionados principalmente pela ação antrópica. É importante enfatizar que a noção de ambiente deve incluir o ser humano, uma vez que há uma relação entre ser humano e ambiente. Diante disso, a questão ambiental observada através dos desenhos é uma ferramenta essencial de percepção da realidade vivenciada pelos alunos.

Além disso, os alunos demostraram conhecimento em relação a separação correta do lixo nas lixeiras, porém, poucos sabem sobre o processo de reciclagem. Sendo assim, houve uma preocupação devido à falta de informações sobre a reciclagem, por isso, a intervenção pedagógica foi uma alternativa muito importante objetivando ensinar os conceitos e processos de tratamento dos resíduos sólidos e demais assuntos sobre a Educação Ambiental.

Desse modo, foi identificado após a intervenção pedagógica que os alunos conseguiram desenhar as novas lixeiras que antes não conheciam, demostrando os novos conhecimentos construídos. Isso revela o quanto é importante abordar a Educação Ambiental nos ambientes escolares, contribuindo para que os alunos possam ter conhecimento das práticas de reciclagem, e principalmente, na conservação do ambiente.

Sendo assim, o estudo da percepção ambiental no local escolhido pode contribuir para um melhor conhecimento das relações humano-ambiente. Dessa forma, podem auxiliar para o desenvolvimento de uma melhor relação do Homem com a natureza buscando práticas sustentáveis. Acredita-se que, se a Educação Ambiental for pautada na realidade local, provavelmente os alunos se tornarão capazes de cuidar do meio ambiente, assim como, realizando a reciclagem como uma alternativa para minimizar os impactos ambientais.

Nesse sentido, o referido trabalho poderá subsidiar futuras pesquisas que tenham em seu escopo a utilização da intervenção pedagógica utilizando-se da metodologia que ora foi empregada nesse estudo para as diversas temáticas que cerceiam à Educação Ambiental.

\section{Referências}

ABRELPE - Associação Brasileira de Empresas de Limpeza Pública e Resíduos Especiais. (2019). Panorama dos resíduos sólidos no Brasil $2018 / 2019$.

Alencar, M. M. M. (2005). Reciclagem de lixo numa escola pública do município de Salvador. Revista Virtual, 1(2), 96-113.

Aquino, I. F. D., Castilho Jr, A. B. D., \& Pires, T. S. D. L. (2009). A organização em rede dos catadores de materiais recicláveis na cadeia produtiva reversa de pós-consumo da região da grande Florianópolis: uma alternativa de agregação de valor. Gestão \& Produção, 16(1), $15-24$. 
Barboza, L. A. S., Brasil, D. D. S. B., \& Conceição, G. D. S. (2016). Percepção ambiental dos alunos do $6^{\circ}$ e do $9^{\circ}$ anos de uma escola pública municipal de Redenção, Estado do Pará, Brasil. Revista Pan-Amazônica de Saúde, 7(4), 11-20.

Bezerra, L. S. et al. (2017). Coleta seletiva: percepção dos alunos de uma escola do ensino fundamental. Revista Scire, 13(2), 1-12.

Brasil. (1998). Parâmetros Curriculares Nacionais: temas transversais: meio ambiente: 10(3), 38.

Brasil. (2010). LEI 12.305/2010. Política Nacional de Resíduos Sólidos.

Caldeira, C. S., Nunes, A. L. R., \& Morales, A. G. (2012, May). Mapeamento dos projetos de educação ambiental do ensino fundamental. In $9^{a}$ ANPED SUL.

Cândido, V. (2013). A reciclagem como instrumento da conscientização e preservação ambiental. Monografia (Especialização em Educação Ambiental-EaD). Universidade Federal de Santa Maria.

Carvalho, N. L. et al. (2020). Percepção ambiental de alunos do ensino fundamental no município de Tupanciretã/RS. Revista Monografias Ambientais, 1(7), $1-17$.

Catanhede, A. M. et al. (2016). Análise da percepção ambiental, por meio de desenhos, de alunos do ensino fundamental numa escola da zona rural, Chapadinha-MA. Revista da SBEnBio. 9, 6561-6570.

CONAMA - Conselho Nacional de Meio Ambiente (Brasil). (2001). RESOLUÇÃO CONAMA n ${ }^{\circ} 275$, de 25 de abril de 2001 80. Estabelece o código de cores para os diferentes tipos de resíduos, a ser adotado na identificação de coletores e transportadores, bem como nas campanhas informativas para a coleta seletiva. Diário Oficial da República Federativa do Brasil, Brasília, 19 jun. 2001.

Corrêa, A. P. M., \& da Silva, M. E. (2013). A logística reversa sob a perspectiva produção-mercado-consumo: o caso O Boticário. Revista de Gestão Ambiental e Sustentabilidade, 2(1), 97-122.

Garçone, C. D. O. (2019). Toró: jogo de tabuleiro educativo com ênfase no ensino de reciclagem. Monografia (Graduação em Desenho Industrial - Projeto de Produto) - Escola de Belas Artes, Universidade Federal do Rio de Janeiro, Rio de Janeiro.

Gil, A. C. (2006). Como elaborar projetos de pesquisa. (4a ed.), Atlas.

Gonçalves, A. A., Lima, M. E. O., \& Marques, M. R. (2009). A percepção e educação ambiental com alunos do ensino fundamental. ed: Centro Universitário de Belo Horizonte, Departamento de Ciências Biológicas Belo Horizonte, MG, 1- 15.

Gonzalez, A. H., \& Rocha, M. B. (2019). Análise da percepção ambiental de estudantes sobre a Baía de Guanabara através de desenhos. Research, Society and Development, 8(9), e04891239-e04891239.

IBGE, Instituto Brasileiro de Geografia e Estatística. (2019). Cidades e Estados. https://www.ibge.gov.br/cidades-e-estados/pa/braganca.html.

Leff, E. (2012). Saber ambiental: sustentabilidade, racionalidade, complexidade, poder. (9a ed.), Vozes.

Marconi, M. A.; Lakatos, E. M. (2010). Metodologia científica. (5a ed.), Atlas.

Pereira, K. N. S. et al. (2016). Percepção Ambiental dos alunos do Ensino Fundamental da escola estadual Angelina Franciscon Masutti do município de Campos de Júlio - MT. Revista Gestão Universitária, 6, 1-13.

Profice, C. C. et al. (2013). Janelas para a percepção infantil de ambientes naturais. Psicologia em Estudo, 18(3), 529-539.

Rouquayrol, M. Z.; \& Almeida Filho, N. (1999). Epidemiologia e saúde. (5a ed.), Medsi.

Sachs, I. (1986). Ecodesenvolvimento, crescer sem destruir. Ed. Vértice, 289 p.

Santos, F. A. S.; \& Teixeira, L. N. (2017). Percepção ambiental e análise de desenhos: prática em curso de extensão universitária. Revista Brasileira de Educação Ambiental, 12(2), 156-177.

Sauvé, L. (2005). Educação Ambiental: possibilidade e limitações. Educação e pesquisa 31(2), 317-322.

Silva, L. J. C. (2013). Estudo da percepção ambiental dos alunos do ensino médio no Colégio Estadual Manoel de Jesus em Simões Filho, BA. Monografia de especialização (Pós Graduação em Gestão Ambiental) - Universidade Tecnológica Federal do Paraná, Medianeira.

Soares, C. V. C. O. (2005). As intervenções pedagógicas do professor em ambientes informatizados: uma realidade a ser construída. Dissertação (Programa de Pós-Graduação em Educação), Universidade Federal do Rio Grande do Sul.

Souza, G. S., Machado, P. B., Reis, V. R., Santos, A. S., \& Dias, V. B. (2014). Educação ambiental como ferramenta para o manejo de resíduos sólidos no cotidiano escolar. Revista Brasileira de Educação Ambiental (RevBEA), 8(2), 118-130.

Telles, C. A. \& Silva, G. L. F. (2012). Relação criança e meio ambiente: avaliação da percepção ambiental através da análise do desenho infantil. Revista Tecnoeng. 6(3), 23-40.

Torres, K. M. S. (2010). A percepção dos alunos do ensino fundamental da escola municipal Joana D’arc do municipio de Tangará da Serra - MT. Monografia apresentada ao Departamento de Ciências Biológicas da UNEMAT - Campus Tangará da Serra.

Trevisanuto, T. M. C. (2019). Logística Reversa de embalagens Pet no Brasil. Revista FIBiNOVA, 1(1), 1-18.

Tuan, Yi-Fu. (1980). Topofilia: estudo da percepção, atitudes e valores do meio ambiente. Ed. DIFEL.

Valle, C. E. (1995). Qualidade ambiental: como ser competitivo protegendo o meio ambiente. Pioneira.

Zago, J. P., Rocha, M. B., \& Costa, I. J. O. (2020). Estudo sobre Percepção Ambiental de Visitantes no Parque Nacional da Tijuca. Research, Society and Development, 9(1), e81911675. https://doi.org/10.33448/rsd-v9i1.1675. 